\title{
In Excess, Elsewhere and Otherwise: Feminine Subjectivity in Eija-Liisa Ahtila's multi-screen installation If 6 Was 9 (1995)
}

\author{
ELSPETH MITCHELL, University of Leeds
}

\begin{abstract}
This paper engages with the concept of 'elsewhere' in the feminist philosophy of Luce Irigaray as a way to theorise the experience of viewing the audio-visual installations of Finnish artist, Eija-Liisa Ahtila. Ahtila's work traces specific narratives concerning feminine desire and subjectivity across multi-screen apparatus in gallery environment. The space of exhibition and film form initiate a mode of encounter that motivates a different relation of projector, screen and viewer. Ahtila's multi-screen installations insist that we look to the places of exclusion in discourse and to the silences in representation for meaning elsewhere, in excess and otherwise. The exclusion in discourse is for Luce Irigaray of course the feminine. Irigaray articulates a view that textually and performatively demands we recognise the impossibility of a feminine position. I take up this problematic with specific attention to how Ahtila's audiovisual installation If 6 Was 9 (Jos 6 olis 9, 1995) produces and disrupts traditional cinematic representation to examine how the space of installation, multi-screen form and the filmic space lend itself to a different encounter with the cinematic. By tracing the concept of 'elsewhere' in philosophical and audio-visual texts, the article develops and refines a position from which one might view contemporary cinematic experience.
\end{abstract}

\section{KEYWORDS}

Luce Irigaray, Eija-Liisa Ahtila, feminism, feminist film, moving image installation, expanded cinema, gallery film 


\section{Introduction}

Eija-Liisa Ahtila (b. 1959) is a Finnish artist and filmmaker best known for her multiscreen gallery installations that explore sexuality, trauma, subjectivity and relationships. These audio-visual works focus on surreal narratives, often in domestic settings, blending documentary and drama together to produce a distinct approach to space and temporality. Ahtila has said that instead of just getting characters to talk about feminist issues, I wanted to incorporate feminism deeper into the structure of the works', suggesting that there are different ways to engage with feminist thinking through audiovisual means (Ellis 2002, 48). Others, such as Mieke Bal, have argued for Ahtila's work to be considered as a deeply philosophical mediation on the moving image (2013). But how exactly do Ahtila's multi-screen audio-visual installations interrogate philosophical and feminist concerns? How does this impact on the articulation of space in the field of spectatorship and the scene of representation?

On one level Ahtila engages with feminist concerns through narratives in her films that explore themes of sexuality, desire and subjectivity in women and girls. Yet if we follow the proposition that she aims to incorporate feminism deeper into the structure of the works, what can we discern? I take up this question with specific attention to how Ahtila's audiovisual installation If 6 Was 9 (Jos 6 olis 9, 1995) produces and disrupts 'traditional' cinematic representation, drawing on the feminist philosophy of Luce Irigaray and the writing of film theorist Teresa de Lauretis. Thinking about how both writers develop the notion of 'elsewhere' in their work, I argue that a similar mode is discernable in Ahtila's audiovisual installations. The interventions that feminist theorists such as Irigaray and de Lauretis made in the 1970s and 1980s, in discourses of the subject constructed through film, have made possible the kind of articulation of sexuality and subjectivity that we find in Ahtila's films. I am, therefore, drawing attention to a genealogy of feminist thinking but also a conversation that can be traced over three decades and through the three main 'texts' that this paper examines. Feminist critical interventions have theorised and called into question the sexually differentiated and oppositional structures of representation and discourse articulated in through deconstruction, semiotics and psychoanalytic paradigms. This article builds a bridge between the marginalised feminist questions of representation and feminist philosophy in relation to the development of digital technologies, 
transformations in exhibition and the expanded field of cinema. These developments and transformations require careful consideration in relation to feminist theories of film and spectatorship, something that is outside the scope of this article. Rather, this article provides a close reading of the textual processes of Irigaray's philosophy that provides an analytic framework for a close reinterpretation of cinematic processes and implications of space in Ahtila's installation.

\section{Eija-Liisa Ahtila's audio-visual installations}

In this exploration of Ahtila's multi-screen gallery installation it is important to highlight that Ahtila also produces her multi-screen installations as $35 \mathrm{~mm}$ film. The films are screened at film festivals in a more traditional cinematic setting but have also been inserted into advertisement slots on Finnish television, for example with Me/We (1993), Okay (1993) and Gray (1993). Ahtila's audio-visual installations have been exhibited widely in art galleries and museums including a major exhibition in 2002-2003 that toured the Nykytaiteen museo (Kiasma Museum of Contemporary Art), Helsinki; Tate Modern, London; Dundee Contemporary Arts, and Zurich Kunsthalle. In these contexts the different modes of distribution and exhibition indicate Ahtila's interest in different viewing situations and the possibilities that different modes of presentation offer for spectatorship. The space of viewing becomes important to think about, especially as Ahtila is precise in her instructions for the exhibition of her works and thus the space of viewing becomes an integral and interesting part of Ahtila's traversal of cinematic and artistic modes.

If 6 Was 9 (Jos 6 olis 9, 1995) is a ten minute, three-screen installation that also exists as a split-screen $35 \mathrm{~mm}$ film. The narrative is based on research and interviews with women that inform a drama of events woven together as episodic tales set in Helsinki. It focuses on the characters of five girls who narrate stories exploring personal experience, sexuality and desire. Over eight mini-episodes, ten minutes and three screens, the girls speak directly to the camera, as voice-off or to one another. Here I have made a distinction by using 'voice-off' rather than 'voice over'. Entering debates concerning the terminology of film sound, the notion of the voice-off (generally meaning voice out of shot) is inherited from feminist film theory, most significantly 
in the writing of Mary Ann Doane (1980) and Kaja Silverman (1984). Silverman, for example, uses 'voice-off' as a way to critique the gendered relations of disembodied and embodied voice, resulting from the general assumption in film scholarship that the omniscient disembodied voice was imbued with symbolic patriarchal authority. From a similar perspective Doane develops her notion of 'voice-off' with a comparable critique in mind but one that is more specifically outlined in terms of space. Her concept of 'voice-off' refers to a voice that is off screen but within the diegesis. 'Voice-over' is a voice that comes from beyond the diegesis and an 'interior monologue' refers to when a character is on screen but they are not seen speaking meaning that their voice internalised. These distinctions are important but moreover they allow us to recognise that sound is often ambiguous in terms of pinpointing where it comes from. Ahtila's use of single track audio alongside three screens draws on these different modes of address to complicate and problematise the visual and sonic encounter. Music is played on screen, for example when a girl plays the piano, but we also hear it off-screen. Like the voices of the girls themselves, the piano music complicates the relation of image, sound and viewer. Yet because the sound often leads the edits across and between screens, rather than gesture or looks, an altered relation emerges that fragments the traditional continuities between sound and space in narrative cinema.

In the catalogue to her 2002 retrospective Ahtila writes:

The division and convergence of the three screens reflects the reality of the events as the girls experience them. The narrative is never confined to a single shot, but cuts from one image to the next, simultaneously spilling over into the other two images $(2002,60)$.

Here Ahtila makes a direct connection between her style of editing and the articulation of the experience of girls, drawing our attention to the importance of these forms and how they relate to each other in her work. Formally the three screens present, at various points, different configurations of shots and locations. The three screens come together with a shot of the girls or a shot of a landscape to present the same scene from three different viewpoints. Other times the screens converge to show a single shot split across three screens. The screens will repeat the same view three 
times or divide to show a different location shot on each screen. The multiple screens create opportunities for associative links or discordant relations that would not necessarily be possible in a more traditional cinematic form. The formal style offers and opportunity for us to think about other ways of looking that are engendered by these audio-visual artistic strategies. There is a disruption of the binary oppositions that structure the scene of representation and the gendered notion of the gaze (Mulvey 1975). An important aspect of the film's experimentation is the discordant articulation of the filmic time and space that creates subtle incoherencies in what would at first seem to resemble a linear narrative style. In classic cinema, the first location shot would set the scene by establishing a time and place for the sequence. Ahtila's shots are conceived without spatial cues to unify or connect them in time and space. Paradoxically, the destabilising potential of the triple-screen projection is employed without losing the style of linear narrative for it is deep within the style itself that the inconsistencies are worked. Thus as we watch we gently realise the grounding of uncertainty and incoherence that underlies the entire film. Yet the high production values of the film and the single-track audio ensure narrative and illusory coherence therefor a deliberate tension is created between form, content and physical space. Each screen also has a very wide aspect ratio, which means the viewer is inclined to move their body in an attempt to see the three screens. This is an important point to return to when we consider the articulation of space and the viewer in the installation.

The space of exhibition, the multiscreen format and the editing style allow If 6 Was 9 to be read as a discursive space of encounter engaging with traditional, patriarchal and phallocentric modes of representation and discourse. This presents a parallel with the philosophical thought of Luce Irigaray and Teresa de Lauretis particularly in terms of reading the installation as a "view from "elsewhere" (de Lauretis 1987, 25). By thinking about how Irigaray and de Lauretis conceptualise 'elsewhere', the aesthetic form of the installation becomes readable as producing an encounter that may refute the systems of phallocentrism and the conditions of patriarchal regimes in visual culture. It is here where a feminist modality, to re-read and re-write is politically and philosophically appropriate. 


\section{'Elsewhere' and Luce Irigaray}

In her book This Sex Which Is Not One Luce Irigaray argues that culture, as it stands, only describes and represents one sex — the masculine (1985). What is perceived as sexual difference is actually sexual indifference because only the masculine can be posited, reproduced and naturalised as the universal. Irigaray's articulation of this argument is important for several reasons. By concerning her writing with the importance of the problem of sexual difference, which is to say by suggesting sexual difference does not exist in culture as it stands, she persuasively emphasises the impossibility of the feminine position as subject and how the notion of the feminine provides the necessary ground, as lack, for phallocentric operations. In Irigaray's philosophy we are asked to perform a mode of reading (a reading of discourse, representation, culture) that pays attention to 'procedures of repression, to the structuration of language that shores up its representations, separating the true from the false, the meaningful from the meaningless' (Irigaray 1985, 75). Her writing reflects this argument and through her performative textual strategies Irigaray also suggests the kinds of work that might productively oppose phallocentric forms to open up a space for another kind of representation or encounter. To do this she takes up the master discourses of Western philosophy from Plato to Freud to interrogate and make visible how the texts naturalise masculine structures to posit them as universal ones, but also how they ceaselessly draw upon the feminine/maternal as the unacknowledged resource for their formation. It is these strategies, which develop a deconstructive and fundamental critique of philosophy and culture and also elaborate radical strategies that create a space to oppose these forms, which mark Irigaray's writing as particularly significant.

\section{'Elsewhere': a deconstructive strategy}

Irigaray conceptualises 'elsewhere' in three ways: a deconstructive strategy; a concept related to her notion of mimesis; a concept that implies a certain movement and spatiality in desire. First 'elsewhere' is a concept that enables Irigaray to further elaborate her central critiques of culture. She writes that: 
[...] if women are such good mimics, it is because they are not simply resorbed in this function. They also remain elsewhere: another case of the persistence of "matter," but also of "sexual pleasure."

That "elsewhere" of female pleasure might rather be sought first in the place where it sustains ek-stasy in the transcendental. [...] Feminine pleasure has to remain inarticulate in language, in its own language, if it is not to threaten the underpinnings of logical operations. (1985, 77)

In this section Irigaray poetically elaborates a complex notion of 'elsewhere' and 'feminine pleasure', touching on the different ways she will come to describe the concept. She proposes feminine pleasure as 'elsewhere' but also as an unspeakable language that threatens traditional logical structures. The positionality that 'elsewhere' connotes - a place that is not here - is integral to describing the structural impossibility of a sexuality that is not based upon masculine parameters. By describing the 'elsewhere' of feminine pleasure Irigaray draws attention to the portrayal of the feminine as outside, but at the same time showing the impossibility of this position. The refusal of a specificity of feminine desire provides the conditions which shore up a phallocentric system and shows how what is refused, the feminine, is already inside phallocentrism as its necessary outside. The notion of 'elsewhere' is also not just a critique but a strategic act. It articulates the paradox of how to represent when representation is based on the refusal of the thing you are trying to bring into representation. The 'elsewhere' of feminine pleasure therefore acts as a strategic theoretical wedge. It provides a focus that, due to the connotations of the word and its textual implementation in Irigaray's philosophy, at once displaces and creates a space for thinking otherwise.

From this perspective we can develop the idea of an 'elsewhere of feminine desire' further in respect of the encounter with representations of sexuality and subjectivity in Ahtila's installation. The feminine, following Irigaray, is never where we are, that is to say it does not sit in the realm of our sensible comprehension. It is the paradox of the outside that is inside and it refutes the systematicity of the logics of place and 
definition. In this reading we can see how Irigaray's strategy takes a similar approach to Jacques Derrida and deconstruction more broadly. Whilst Irigaray's work speaks to deconstructive modes of critique as an initial strategy, it nevertheless also aims to open up a space to explore the possibilities of, and necessity for, a feminine imaginary. As well as the deconstructive critiques that we can discern, Irigaray's notion of 'elsewhere' can be considered as a creative and utopic gesture. Ahtila, who could be considered as facing a similar kind of paradox of representation but in terms of the moving image, mobilises the girls in her films as an embodiment of this notion. As Taru Elfving discusses in her essay 'Haunted: Writing with the Girl', the girls themselves can be read as subversive figures (2011, 107-124). They inhabit domestic and institutional spaces but they are alone. With no mothers, fathers or teachers the world is devoid of adults. The girls, who are the only figures in the film, exist in a filmic space that is unexceptional; in domestic settings and landscapes that would be unremarkable in a traditional narrative film. As I will explore in more detail, the places they inhabit are undercut with a sense of strangeness, which is subtly articulated through the dislocation of figure and space across the installation rather than the location. The filmic space and installation space collude in confounding and subverting a 'proper' sense of place. It is within this arena of placeless-ness that the girls talk freely of their experiences of pleasure and their desires. Strategic placelessness or the subversion of proper place is employed to help mediate the articulation of feminine desire. Thus Ahtila's film allows the girls to speak frankly and with great detail or imagination about desire, sexuality and sexual experiences.

\section{'Elsewhere': Mimesis}

Another way that Irigaray uses the concept of elsewhere is in relation to her theories of mimesis and femininity. According to Irigaray, women's skills in the mimicry of femininity (a phallocentric façade that is a falsely defined as an attribute of women) prove that women 'also remain elsewhere' $(1985,76)$. That is to say, Irigaray suggests that women's skill in reproducing or parodying femininity alludes to their being in excess of this construct. The active re-play through mimesis 'unveils' the functions and mechanics which the phallocentric system tries so hard to universalise and cover up. Inconsistencies become apparent through this play, therefore, it is 
through this action that Irigaray is able to insist that women have the possibility to exist 'elsewhere' of femininity. Women can parody universalised roles, so it follows that there is an excess or resource other than what is 'visible' in the existing symbolic and subjectivising structures. Irigaray makes this clear when she writes:

One must assume the feminine role deliberately. Which means to convert a form of subordination into an affirmation, and thus begin to thwart it [...] To play with mimesis is thus, for a woman, to try to recover the place of her exploitation by discourse, without allowing herself to be simply reduced to it. It means to resubmit herself — inasmuch as she is on the side of the "perceptible," of "matter" — to "ideas," in particular to ideas about herself, that are elaborated in/by a masculine logic, but so as to make "visible," by an effect of playful repetition, what was supposed to remain invisible: the coverup of a possible operation of the feminine in language. (1985, 76)

The strategy of mimesis and the notion of a disruptive excess that Irigaray describes can be related and compared to the acting and dialogue in If 6 Was 9. The dialogue draws on real stories from grown women which the girl actors speak as voice-off, interior monologue and to each other. The effect of the girls speaking women's stories is that at one moment their dialogue seems quite normal and at another moment entirely strange. There is sometimes a disconnection between the girl and what she says. One girl for example talks about a long history of sexual experiences that seem at odds with her age. Others speak plainly of embarrassing subjects which are perhaps not expected of girls. Some, however, play out the role of 'girlhood' without any question. In one episode the girl tells us she is actually a thirty-eight year old woman who has been sent back to girlhood. At this moment we question our own perception of the girl and doubt our judgement of her age. Age, temporality and femininity more broadly are thrown into question in the different girls. Notions of femininity are either played out in line with normative ideals or disrupted. The girls seem to be mimicking women, playing out their stories and embodying the ideals that are conveyed within it. Whilst we sense something is strange in this re-play of women's stories through the 
figures of girls we are left unsure of how much these tales might actually belong to the girls. It is a kind of ventriloquism but one which complicates the agency and position of who is speaking. This form reflects on the critique of the production of femininity in a similar way that Irigaray reflects upon it. Instead of women replaying the role of Woman, however, it is the girl taken as a subversive figure, who can speak and play out femininity to specifically disrupt the sense of subjectivity.

In her book The Desire to Desire Mary Ann Doane describes Irigaray’s mimetic texuality as enacting a 'defamiliarising version of femininity' and advocates for it as a political textual strategy in relation to female spectatorship $(1987,182)$. Doane's work forms part of an important landscape of feminist theories of film, which from the mid1970 s to the early 1990s took up the question of images of woman and female spectatorship. Laura Mulvey's essay 'Visual Pleasure and Narrative Cinema' theorised the binary oppositions of active/passive and subject/object that structured cinematic pleasure through the gaze in Hollywood cinema (1975). These theoretical interventions created an arena for feminist counter cinemas to explore modes of cinematic representation that rejected conventions that positioned woman as a passive object of desire. Mary Ann Doane describes how examples such as Jeanne Dielman, 23 Quai Commerce -1080 Bruxelles (1975) by Chantal Akerman, Riddles of the Sphinx (1977) by Laura Mulvey and Peter Wollen and Thriller (1979) by Sally Potter disrupt a classic 'syntax' of cinema in relation to the gaze and the image of woman (1991, 176-177). Provocatively, one can be informed by these feminist interventions in film when reading the work of Ahtila, however the girls in If 6 Was 9 occupy a space that is not the 'images of woman' that Doane and Mulvey take on. As girls they resist the homogenous categorisation of woman but also reframe notions of female sexuality through what they say. They become active agents of desire through their dialogue yet this can only go so far. As mimesis can only unveil the workings of femininity that is demanded of the feminine subject it is the dynamics of space, the (dis)articulation of vision or sound and the figure of the girl that engender a feminist transformation of the cinematic experience. 


\section{'Elsewhere': Space and Movement}

Irigaray evokes a sense of space, place and movement when describing a notion of the 'elsewhere' of feminine desire. Not only does she write of the 'elsewhere' of feminine desire but she describes the moves in which it may be produced or located:

That "elsewhere" of feminine pleasure can be found only at the price of crossing back through the mirror that subtends all speculation. For this pleasure is not simply situated in a process of reflection or mimesis, nor on one side of this process or the other; neither on the near side, the empirical realm that is opaque to all language, nor on the far side, the self-sufficient infinite of the God of men. [...] A playful crossing, and an unsettling one, which would allow woman to rediscover the place of her "self-affection." (Irigaray 1985, 77)

Irigaray describes a crossing of different sides of a mirror and a crossing between the empirical realm of law and infinite realm of God. It is through 'a playful crossing, and an unsettling one' that may allow the 'place' of feminine self-affection to be found (Irigaray 1985, 77). The metaphor of movement between places, or in discovery of a place, is strongly evoked in these phrases. Her metaphorical description is not of a real space, but uses the idea of a movement to imagine how we might locate feminine specificity amongst the structures that refute it.

This form of movement resonates with Ahtila's rapid style of editing across the screens creating patterns of dissonance but also mellifluous rhythms. Drawing on Lev Manovich's proposal of 'spatial montage' in multi-screen installation we can emphasise how Ahtila's work also creates a spatial form (Manovich 2001, 325). In this sense, montage is not happening simply within the screen but between and across screens, as a sort of double montage that implicates space in the scene of the installation. In the fictive world created by Ahtila's moving-image installation, she provides a productive arena for the close interplay of time and space. Alison Butler's description of the 'obtrusive editing' captures eloquently the foregrounding of edits in If 6 Was 9 (2005, 23). Ahtila's editing disallows our complete envelopment into 
illusion. Instead it draws attention to the possibilities of multiple points of view. If we think about the traditional cinematic form, identification and the illusion of a singular perspective are created through techniques such as the shot/reverse-shot. In the case of the installation we see adherence and divergence from what we might think of as the standardised language of cinema. The space of encounter is integral to this effect and provides an arena that we negotiate as an active, embodied viewer. For example Ahtila makes good use of the ability to repeat images across the two or three screens. Shots converge into a panorama or veer off with quick edits and fast paced changes of location. At certain points perspectives are constructed from three different angles across all of the screens. With the fast edits and the multiple screens we are drawn into a pattern of looking that creates a sense of an interactive environment rather than a fixed position from which we objectively view. The viewpoint is encouraged to be doubled, tripled or dispersed, whilst it is also impossible cognitively to see everything at once. Movements produced through editing or enacted within the film's diegesis are emphasised because of the extreme aspect ratio. When displayed in a gallery Ahtila provides specific technical instructions for the installation. If 6 Was 9 must have, across all three screens, an aspect ratio of almost 1:4. The size of the projected image must be relative to the size of the room but each screen cannot be less than two and a half meters wide (Butler 2005, 23). The patterns of dissonance are enhanced laterally by the wide set up. This means that the spectator will literally have to move their body to view it.

The potential of this strategy is evident in a scene that involves a girl called Päivi. Fascinated with the story of the Pied Piper seen in the cartoon slides of a View Master Toy, Päivi focuses on two frames from the View Master that illustrate the end of the story. In the tale the Pied Piper leads the children of Hamlin into a cave on the side of a mountain and they are never seen again. Following the View Master's cartoon depiction, the left and centre screens show the two frames illustrating the story that Päivi obsesses over - one with the children being led into the cave and one which shows the hole closed up. The two screens switch back and forth between one illustration on one screen and the other illustration on the other, alternatively with the black leader. The alternating editing sequence creates a pattern from left to right that makes us look to the right screen at the point where the repetition stops and instead of the cartoon we see a man's naked bottom. 

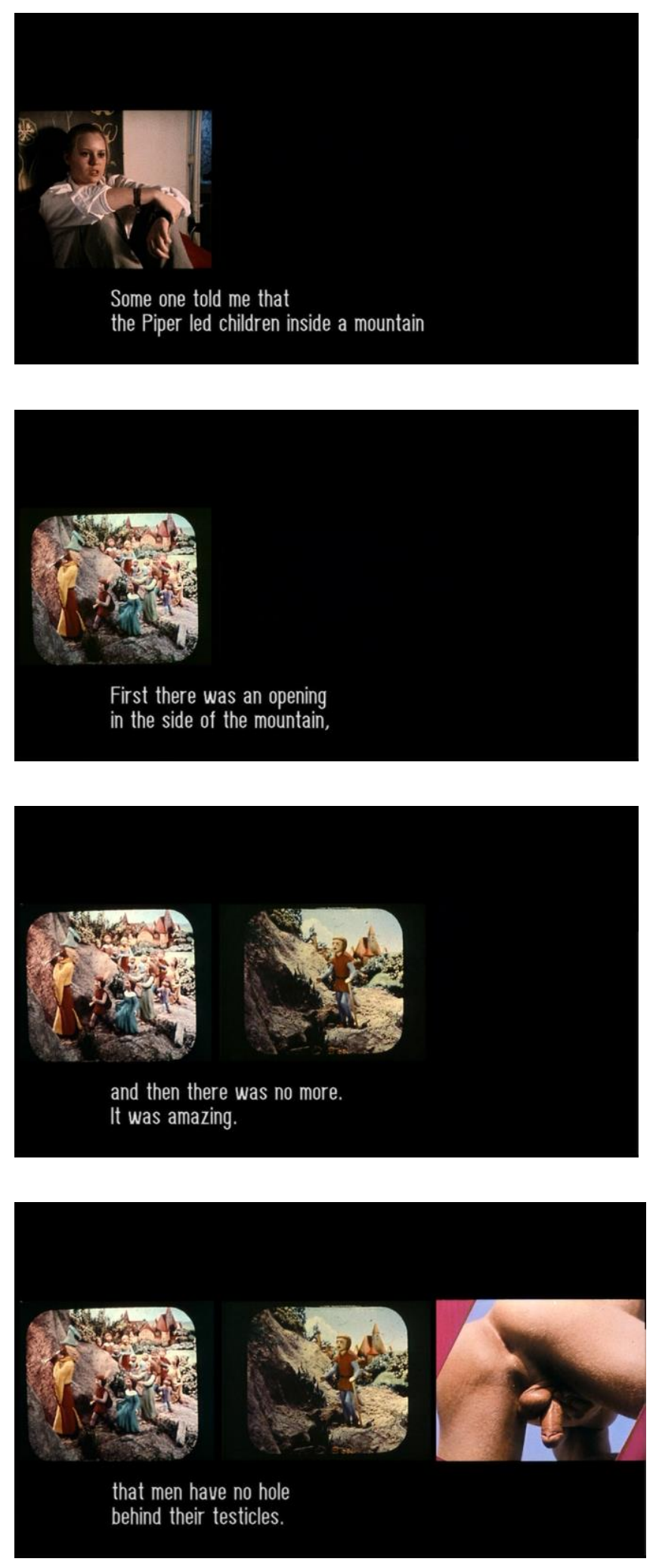

Figure 1-4: Eija-Liisa Ahtila, If 6 Was 9 (1995) DVD from BFI and Crystal Eye.

Päivi's voice-off consolidates the meaning to be inferred by the closing of the mountain cave, she says, 'It was equally amazing to see in a porno magazine that men have no hole behind their testicles. I thought that it couldn't have always been like 
that always' (Ahtila, 1995). In an ironic reversal of the terms that designate the women's body as 'lack', Päivi interprets the man's lack of two holes as a surprising revelation. The sequence's rhythm engages us to follow the screens, but at other times it leads us astray. We make the same leap as Päivi easily because of the persuasive and engaging rhythm of the screens that draws us from left to right. The editing constructs certain meanings through its lateral associations but also deconstructs or displaces certain given meanings. The installation's engagement with the body in space takes this even further. The embodied movements of the viewer in the space of encounter implore us to engage with certain meanings that, as we have seen, are clearly feminist in intent. I would also argue, however, that the movement itself also speaks to feminist considerations. The choreography of editing enacts a play of movement that, as we have seen, is similarly thought through in Irigaray's philosophy. It is through strategies like these that show how Ahtila is thinking about incorporating a critical feminism deeper into the structures of her works.

\section{'Elsewhere' and Teresa de Lauretis}

Feminist film theorist, Teresa de Lauretis uses the term 'elsewhere' in a way that engages with Irigaray's senses of the term and is useful for thinking what the potential of 'elsewhere' might be for feminism and feminist cultural production. If feminist theories are at risk of simply rearticulating phallocentric narratives and structures under a different name, de Lauretis argues that feminism must work to resist this by critiquing all discourses, including those of feminism, with the means to figure a 'view from "elsewhere"' $(1987,25)$. Similarly to Irigaray, this 'elsewhere' is not a utopian future but a specific call to work in the margins and interstices of institutions, discourses and modes of representation:

For, if that view is nowhere to be seen, not given in a single text, not recognisable as a representation, it is not that we feminists, women - have not yet succeeded in producing it. It is, rather, that what we have produced is not recognisable, precisely, as a representation. For that "elsewhere" is not some mythic distant past or some utopian future history: it is 
the elsewhere of discourse here and now, the blind spots, or the space-off, of its representations. (de Lauretis 1987, 25)

Here de Lauretis is bringing into focus the question of how to write, represent and signify an 'elsewhere' when ideological and cultural productions are built from the singular view of masculinity and to be more precise the hegemony of white Western masculinity. She calls for the theoretical construction of a 'subject of feminism' constituted by a constant work of rewriting and rereading to produce the possibility of the view from 'elsewhere' (de Lauretis 1987, 25-26). De Lauretis acknowledges that the 'elsewhere' that such work produces may not be recognisable qua representation. She stresses the importance of work that opens spaces for modes of signification, reading and spectatorship in relation to the 'space-off' of representation and discourse. De Lauretis develops the notion of 'space-off' to help figure the notion of 'elsewhere' borrowing from film theory that refers to that which is not in the frame but is inferred by it (de Lauretis 1987, 26). The space-off in classic cinema is erased or sealed into the image by narrativisation. Systems such as shot/reverse-shot contain the space-off, make it point or look inward rather than outward or elsewhere. Avant-Garde films and filmmakers have problematised this system. By articulating different perspectives, editing techniques or framing, through which it is possible to point to where the space-off is, where it is invisible. Likewise, the voice in film is integral to the narrative unity or disunity of the scene of representation. As we have seen in Doane and Silverman's theorisation of the voice-off, the voice in classic cinema has been used to produce gendered and binary positions that are related to notions of embodiment and the disruption of cinematic space. The voice and sound in film, in this sense, also hold an important role in thinking about the 'elsewhere' de Lauretis gestures toward for feminist cultural production.

Similar to Irigaray's diagnosis, de Lauretis sees the eliding of difference as endemic in cultural production. One strategy describes a movement for the feminist subject that de Lauretis calls upon. This movement is back and forth, in and out of what representation makes visible and what it leaves out $(1987,26)$. It is not a dialectical movement but a movement of contradiction and heteronomy. Thus it is not a movement outside, but a movement 'elsewhere'. Irigaray's description of mimetic play through and back through the mirror of speculation is echoed in de Lauretis' own 
image and Ahtila's editing style. They call upon an image of movement that crosses space back and forth, a crossing of boundaries and limits. De Lauretis tells us specifically that this is 'a movement from the space represented by/in a representation, by/in a discourse, by/in a sex-gender system, to the space not represented yet implied (unseen) in them.' It is the space of the space-off, or the place of elsewhere.

An analysis of the first scene of If 6 Was 9 allows us to directly think about how the figure of the girl relates to the view from elsewhere. In the first sequence, after an initial triptych of shots depicting Helsinki at dusk, the screens come to a supermarket called Maxi where a girl, Päivi, is waiting outside. On the right screen we see the car park in front of the store and a car with headlights slowly drives. The centre screen shows a wide-angle shot from the left of Maxi supermarket. We are presented with two different location shots from different points of view depicted simultaneously on two screens of the three screens. The left screen depicts a close up of Päivi, her head in shadow as the oversized letters of the supermarket sign are illuminated behind her. On the left screen we watch Päivi in close up as she waits outside the supermarket looking around. Having set this scene the centre screen changes to a mid-shot where the automatic doors of the supermarket are opening and shutting. In the distance here we notice another girl, Satu, with a bag of shopping coming out of the store. Päivi and Satu meet outside and they walk off together.

This seems like a straightforward and everyday scene of a girl waiting for her friend. Except underneath this sense of normality things are not quite so straightforward. I have suggested how space is subtly disjointed by the absence of spatial cues, however within the action the figures are fragmented too. As Satu appears through the opening doors of the centre screen we see Päivi disappear out of shot from the left screen. Päivi doesn't appear anywhere else and she is lost to us for several moments.

Eventually what seems to be her, a figure walking into the centre screen, appears. But the shot cuts to black leader before we can be sure. Our queries are answered when a new view of the front of the supermarket shows Satu followed by Päivi who comes into shot a beat or two after. Päivi is depicted again moments later as the girls walk away from the supermarket on the centre screen. The right screen remains black until they are out of shot on centre. With the empty frame still focusing our gaze centrally, Satu appears on the left screen walking down the same section of street. It is framed 
slightly closer than the shot on the centre screen but you are able to notice that Päivi is not next to Satu as expected. Ahtila lines up the screens and edits to suggest continuity, but the disappearance of Päivi casts doubt on the scene. The figure of Päivi has traversed the three screens horizontally, but has also disappeared and taken obtuse, diagonal pathways. It has taken three different viewpoints that do not match up to complete this movement from left screen to right screen and back. Päivi comes in and out of space from unexpected angles and is not confined to a single shot or point of view. Instead her figure spills over into all three viewpoints - fragmented and refuting continuity. The effect is subtle but perceptible.

\section{Conclusion}

Eija-Liisa Ahtila's audio-visual gallery installation offers a distinct perspective on developments in moving-image art practices, exhibition and spectatorship. Through the lens of feminist philosophy and feminist theories of film we can discern ways in which the cinematic space and traditional modes of spectatorship have been refigured and disrupted. These challenges are important as they encourage us to rethink our experience of the moving image in a way that is strongly allied with de Lauretis' provocations for feminist cultural production. On the other hand the opening up of practices and discourses of cinema in relation to a burgeoning digital culture and new modes of experiencing cinema could also offer a way through the perceived theoretical impasse of feminist film theory today. Thinking through viewer's encounter with the screen in the space of exhibition, and not just semiotic or psychoanalytic frameworks in the scene of representation, is integral to the theorisation of this kind of moving-image practice. By foregrounding the opportunities afforded by cinema in exhibition, of multi-screen installation and other modes of presentation, Ahtila's work provides us with an example of an encounter with difference. Difference, in this sense, is figured when we can glimpse the possibility of feminine desire, articulated in the traditionally phallocentric scene of representation. Through the figure of the girl; the multi-screen format and the editing style If 6 Was 9 mobilises and disrupts the traditional cinematic form by invoking an encounter with 'elsewhere' that I have traced through this article. Therefore I argue that contemporary cinematic experience and more specifically digital audio-visual art 
practices, speak to the discourses of feminist theory but that these theories also have a lot to offer the theorisation of screens, bodies, space and technology currently in the expanded field of cinema.

\section{References}

Ahtila, Eija-Liisa, (1995) Jos 6 Olis 9//f 6 Was 9, [DVD].

Bal, Mieke, (2013) Thinking in Film, London \& New York: Bloomsbury Publishing

Balsom, Erica, (2003) 'A Cinema in the gallery, a cinema in ruins', Screen, 50, 411-427

Bonnefoy, Françoise and Claire Bonnevie, eds. (2003) Eija-Liisa Ahtila, Ostfildern: Hatje Cantz Verlag

Butler, Alison, (2010) 'A deictic turn: space and location in contemporary gallery film and video installation', Screen, 51, 305-323

Butler, Alison, (2005) 'Feminist Film in the Gallery: if 6 Was 9', Camera Obscura, 20, 1-31

De Lauretis, Teresa, (1987) Technologies of Gender, Bloomington and Indianapolis: Indiana University Press

Doane, Mary Ann (1980) 'The Voice in Cinema: The Articulation of Body and Space", Yale French Studies, 60

Doane, Mary Ann, (1987) The Desire to Desire: The Woman's Film of the 1940s, Bloomington: Indiana University Press

Doane, Mary Ann, (1991) Femme Fatales: Feminism, Film Theory, Psychoanalysis, New York and London: Routledge 
Elfving, Taru, (2002) 'The Girl' in Fantasized Persons \& Taped Conversations, Helsinki: Crystal Eye

Elfving, Taru, (2011) 'Haunted: Writing the Girl' in Girls! Girls! Girls! In Contemporary Art, Catherine Grant and Lori Waxman eds., Bristol: Intellect Press, 107-124

Ellis, Samantha, (2002) 'Eija-Liisa Ahtila', Make 92

Freud, Sigmund, (2002) 'Female Sexuality', Freud on Women, ed. Elisabeth Young-Bruehl, London: Vintage

Fowles, Catherine, (2004) 'Room for experiment: gallery films and vertical time from Maya Deren to Eija-Liisa Ahtila', Screen, 45, 324-343

Irigaray, Luce, (1985) Speculum of The Other Woman, trans. Gillian C. Gill, Ithaca, New York: Cornell University Press

Irigaray, Luce, (1985) This Sex Which Is Not One, trans. Catherine Porter, New York: Cornell University Press

Irigaray, Luce, (1993) An Ethics of Sexual Difference, trans Carolyn Burke and Gillian C. Gill, Ithaca, NY: Cornell University Press

Irigaray, Luce, (1993) Sexes and Genealogies, trans. Gillian C. Gill, New York: Columbia University Press

Koivunen, Anu, (2013) 'Force of Affects, Weight of Histories in Love is a Treasure' in Carnal Aesthetics: Transgressive imagery and feminist politics, eds. Bettina Papenburg and Marta Zarzycka, London \& New York: I.B. Tauris Manovich, Lev, (2001) The Language of New Media, Cambridge, MA: MIT Press 
Mulvey, Laura, (1975) 'Visual Pleasure and Narrative Cinema' Screen, 16, 618

Myers, Terry, (1999) 'Time Wounds All Heals', ART/TEXT, 66 60-64.

Paflik-Huber, Hannelore, (2001) 'Eija-Liisa Ahtila “Today”, 1996/7', Das Innere Befinden: Das Bild des Menschen in der Videokunst der 90er Jahre (The Inner State: The image of man in the video art of the 1990s), Leichenstein: Kunstmuseum Leichenstein pp.30-39

Philbrick, Jane, (2003) 'Subcutaneous Melodrama: The Work of Eija-Liisa Ahtila', PAJ: a Journal of Performance and Art, 25, 32-47

Pollock, Griselda, (2007) Encounters in the Virtual Feminist Museum: Time, Space and the Archive, London: Routledge

Schor, Naomi, (1994) 'This Essentialism Which is Not One: Coming to Grips With Irigaray', Engaging with Irigaray, eds. Carolyn Burke, Naomi Schor, Margaret Whitford, Columbia University Press

Silverman, Kaja, (1984) 'Dis-Embodying the Female Voice' in Mary Ann Doane, Patricia Mellencamp and Linda Williams, eds Re-Vision: Essays in Feminist Film Criticism, Frederick: University Publications of America

Silverman, Kaja, (1988) The Acoustic Mirror: The Female Voice in Psychoanalysis and Cinema, Bloomington: Indiana University Press

Whitford, Margaret, (1991) 'Irigaray’s Body Symbolic', Hypatia, 6, 3, 97-110

Whitford, Margaret, (1986) 'Luce Irigaray and the Female Imaginary:

Speaking as a Woman', Radical Philosophy, 33, 3-8

Whitford, Margaret, (1991) Luce Irigaray: Philosophy in the Feminine, London \& New York: Routledge 
Yli-Annala, Kari, (2002) 'Talking Selves: on Eija-Liisa Ahtila's Film \& Video Art', in Fantasized Persons \& Taped Conversations, Helsinki: Crystal Eye

Elspeth Mitchell is a PhD researcher at the School of Fine Art, History of Art and Cultural Studies, University of Leeds. Her doctoral project proposes a reading of experimental film and video concerned with girlhood, sexuality and difference through Luce Irigaray's philosophies of sexual difference.

Email: Elspeth Mitchell: fh09erm@leeds.ac.uk 